Article

\title{
Oxytrodiflavanone A and Oxytrochalcoflavanones A,B: New Biflavonoids from Oxytropis chiliophylla
}

\author{
Yang Liu ${ }^{1}$, Norbo Kelsang ${ }^{1}$, Jianghai Lu ${ }^{2}$, Yingtao Zhang ${ }^{1}$, Hong Liang ${ }^{1}$, Pengfei Tu ${ }^{1}$, \\ Dexin Kong ${ }^{3,4, *}$ and Qingying Zhang ${ }^{1, *}$ \\ 1 State Key Laboratory of Natural and Biomimetic Drugs and Department of Natural Medicines, \\ School of Pharmaceutical Sciences, Peking University Health Science Center, Beijing 100191, China; \\ 1311210122@bjmu.edu.cn (Y.L.); kelsang815@163.com (N.K.); zytao1988@163.com (Y.Z.); \\ lianghong@bjmu.edu.cn (H.L.); pengfeitu@bjmu.edu.cn (P.T.) \\ 2 National Anti-Doping Laboratory, China Anti-Doping Agency, Beijing 100029, China; lujianghai@chinada.cn \\ 3 Tianjin Key Laboratory on Technologies Enabling Development of Clinical Therapeutics and Diagnostics, \\ School of Pharmacy, Tianjin Medical University, Tianjin 300070, China \\ 4 Research Center, School of Medicine, Tianjin Tianshi College, Tianyuan University, Tianjin 301700, China \\ * Correspondence: kongdexin@tmu.edu.cn (D.K.); qyzhang@hsc.pku.edu.cn (Q.Z.); \\ Tel.: +86-22-83336659 (D.K.); +86-10-82801725 (Q.Z.)
}

Received: 21 March 2019; Accepted: 11 April 2019; Published: 13 April 2019

\begin{abstract}
Three previously undescribed biflavonoids, oxytrodiflavanone A (1), and oxytrochalcoflavanones A,B $(2,3)$, were isolated from the aerial part of Oxytropis chiliophylla, together with their putative biosynthetic monomers, i.e., (2S)-5,7-dihydroxyflavanone (4), (2S)-7-hydroxyflavanone (5), and $2^{\prime}, 4^{\prime}$-dihydroxychalcone (6). The structures of these compounds were elucidated by a combination analysis of spectroscopic data. The cytotoxic activities of all the isolated compounds against PC-3 human prostate cancer cell line are also presented.
\end{abstract}

Keywords: Oxytropis chiliophylla; Oxytropis; biflavonoids

\section{Introduction}

Oxytropis chiliophylla Royle ex Benth (Leguminosae), along with Oxytropis falcata Bunge, is recorded as the official botanical origin of Tibetan medicine "Er-Da-Xia" in Chinese Pharmacopoeia, which is regarded as the "King of Herbs" and has been widely used in Tibetan medicines for the treatment of inflammation, pyreticsis, and bleeding for thousands of years [1,2]. Mainly found at the altitudes of 2800-5200 meters in Tibet and Xinjiang Urgur Autonomous Regions in China [3], O. chiliophylla was reported to contain a large number of flavonoids as the major bioactive constituents [4-7]. Of these flavonoids, structurally diverse cytotoxic chalcone dimers, isolated from the aerial parts of $O$. chiliophylla by our group, were of great significance in interpreting the hypothesized ecological functions of the chemicals [7]. In an ongoing investigation on the structurally unique and bioactive constituents from O. chiliophylla, we particularly focused on the isolation and identification of other biflavonoids guided by LC-QTOF/MS (Liquid Chromatograph-Quadrupole Time-of-Flight/Mass Spectrometer). As a result, three previously undescribed biflavonoids, oxytrodiflavanone A (1) and oxytrochalcoflavanones A,B $(2,3)$ (Figure 1), were obtained from the aerial parts of $O$. chiliophylla. In addition, their putative biosynthetic monomers, i.e., (2S)-5,7-dihydroxyflavanone (4), (2S)-7-hydroxyflavanone (5), and $2^{\prime}, 4^{\prime}$-dihydroxychalcone (6), were also obtained from the herb. The cytotoxic activities of all isolates were evaluated against the PC-3 human prostate cancer cell line. 


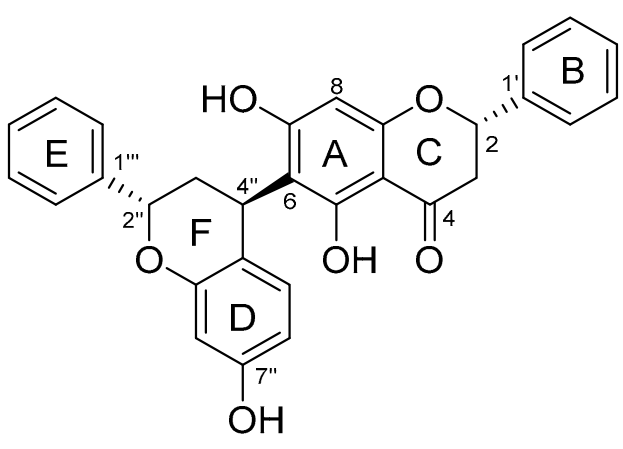

1<smiles>[R]O[Si][Si]</smiles><smiles>O=C1C[C@H](c2ccccc2)Oc2cc(O)ccc21</smiles>

4<smiles>O=C1C[C@H](c2ccccc2)Oc2cc(O)cc(O)c21</smiles>

5<smiles>O=C(/C=C/c1ccccc1)c1ccc(O)cc1O</smiles>

6

Figure 1. Structures of compounds 1-6.

\section{Results and Discussion}

Oxytrodiflavanone A (1), obtained as yellow amorphous powders, had a molecular formula of $\mathrm{C}_{30} \mathrm{H}_{24} \mathrm{O}_{6}$ based on the deprotonated molecular ion at $m / z 479.1499[\mathrm{M}-\mathrm{H}]^{-}$(calcd for $\mathrm{C}_{30} \mathrm{H}_{23} \mathrm{O}_{6}$, 479.1500) in its negative HR-ESIMS (High resolution-Electric Spray Ion Mass Spectrometer) spectrum and NMR (Nuclear Magnetic Resonance) data. The UV (Ultraviolet) spectrum showed maximum absorption bands at 235 and $283 \mathrm{~nm}$. The ${ }^{1} \mathrm{H}$ - and ${ }^{13} \mathrm{C}-\mathrm{NMR}$ data of $\mathbf{1}$ (Table 1) exhibited characteristic signals for a biflavonoid consisting of one 5,6,7-trisubstituted flavanone residue and one 4,7-disubstituted flavane moiety, evidenced by a set of ABX-spin aromatic signals at $\delta_{\mathrm{H}} 6.98(1 \mathrm{H}, \mathrm{d}, J=8.4 \mathrm{~Hz}), 6.55(1 \mathrm{H}$, $\mathrm{d}, J=2.1 \mathrm{~Hz})$, and $6.45(1 \mathrm{H}, \mathrm{dd}, J=8.4,2.1 \mathrm{~Hz})$, overlapped signals for two monosubstituted benzene rings at $\delta_{\mathrm{H}} 7.35-7.46(10 \mathrm{H}, \mathrm{m})$, an aromatic singlet at $\delta_{\mathrm{H}} 6.00(1 \mathrm{H}, \mathrm{s})$, a CH-CH $\mathrm{CH}_{2}$ spin system at $\delta_{\mathrm{H}}$ $5.42(1 \mathrm{H}, \mathrm{dd}, J=13.1,2.5 \mathrm{~Hz}), 3.09(1 \mathrm{H}, \mathrm{dd}, J=17.2,13.1 \mathrm{~Hz})$, and $2.84(1 \mathrm{H}, \mathrm{dd}, J=17.2,2.5 \mathrm{~Hz})$, a $\mathrm{CH}-\mathrm{CH}_{2}-\mathrm{CH}$ spin system at $\delta_{\mathrm{H}} 5.30(1 \mathrm{H}, \mathrm{t}, J=5.0 \mathrm{~Hz}), 4.52(1 \mathrm{H}, \mathrm{t}, J=5.9 \mathrm{~Hz})$, and $2.40(2 \mathrm{H}, \mathrm{t}, J=5.9 \mathrm{~Hz})$, and the corresponding ${ }^{13} \mathrm{C}-\mathrm{NMR}$ signals. The 1D- and 2D-NMR spectra allowed the assignment of all signals. Based on the MS and NMR data, three hydroxyl groups were deduced to be present. The characteristic hydrogen-bonded hydroxyl resonance at $\delta_{\mathrm{H}} 12.58(1 \mathrm{H}, \mathrm{s})$ indicated the presence of 5-OH, and the other two hydroxyl groups were placed at C-7 and C-7", respectively, based on the 1D and 2D-NMR data. The HMBC (Heteronuclear Multiple Bond Connectivity) correlations between $\mathrm{H}-4^{\prime \prime}$ and C-5, C-7, between H-3" and C-6 (Figure 2) established the C-6 and C-4" linkage between the two flavonoid units, which was further confirmed by the characteristic fragment ions at $m / z 223.0760$ and 255.0664 in the targeted MS/MS data that attributed to the cleavage of bond between C-6 and C-4". The $2 S$ configuration of 1 was determined according to the positive Cotton effect at 320 330 nm and negative effect at 270-290 nm (Figure 3) [8], and the 2"S configuration of 1 was tentatively inferred based on the biosynthetic consideration (Scheme 1). The relative configuration of F-ring of $\mathbf{1}$ was deduced to be the same as that of friesodielsone A and desmosflavan A $[9,10]$ according to the coupling constants for $\mathrm{H}-2^{\prime \prime}$, $\mathrm{H}-3^{\prime \prime}$, and $\mathrm{H}-4^{\prime \prime}$, and further supported by the absence of NOE interaction between $\mathrm{H}-2^{\prime \prime}$ and $\mathrm{H}-4^{\prime \prime}$. The absolute 4" $S$ configuration was evident from the positive Cotton Effect at $225.0 \mathrm{~nm}$ (Figure 3) [11-13], and thus allowed the assignment of 2 "S configuration, which was consistent with the above deduction based on biosynthetic consideration. Unambiguously, the structure of $\mathbf{1}$ was characterized as shown in Figure 1 and named oxytrodiflavanone A. 
Table 1. ${ }^{1} \mathrm{H}-\mathrm{NMR}$ and ${ }^{13} \mathrm{C}-\mathrm{NMR}$ data for oxytrodiflavanone $\mathrm{A}(\mathbf{1})(\delta$ in ppm, $J$ in $\mathrm{Hz})$.

\begin{tabular}{|c|c|c|c|}
\hline No. & ${ }^{1} \mathrm{H}-\mathrm{NMR}{ }^{\text {a }}$ & ${ }^{13} \mathrm{C}-\mathrm{NMR}$ & ${ }^{1} \mathrm{H}-\mathrm{NMR}{ }^{\mathrm{b}}$ \\
\hline 1 & - & - & - \\
\hline 2 & $5.42(\mathrm{dd}, 13.1,2.5)$ & 79.17 & $5.56(\mathrm{dd}, 13.2,3.0)$ \\
\hline $3 \alpha$ & $3.09(\mathrm{dd}, 17.2,13.1)$ & 43.69 & $17.02(\mathrm{dd}, 17.0,13.2)$ \\
\hline $3 \beta$ & $2.84(\mathrm{dd}, 17.2,2.5)$ & & $2.89(17.0,3.0)$ \\
\hline 4 & - & 196.11 & - \\
\hline 5 & - & 162.07 & - \\
\hline 6 & - & 109.96 & - \\
\hline 7 & - & 164.13 & - \\
\hline 8 & $6.00(\mathrm{~s})$ & 96.99 & $6.44(\mathrm{~s})$ \\
\hline 9 & - & 161.47 & - \\
\hline 10 & - & 103.12 & - \\
\hline $1^{\prime}$ & - & 138.57 & - \\
\hline $2^{\prime} / 6^{\prime}$ & $7.43-7.46^{\mathrm{c}}$ & 126.26 & $7.24-7.42^{c}$ \\
\hline $3^{\prime} / 5^{\prime}$ & $7.43-7.46^{\mathrm{c}}$ & 129.03 & $7.24-7.42^{c}$ \\
\hline $4^{\prime}$ & $7.43-7.46^{\mathrm{c}}$ & 129.03 & $7.24-7.42^{\mathrm{c}}$ \\
\hline $5-\mathrm{OH}$ & $12.58(\mathrm{~s})$ & - & 13.19 \\
\hline $1^{\prime \prime}$ & - & - & - \\
\hline $2^{\prime \prime}$ & $5.30(t, 5.0)$ & 75.76 & $5.99(\mathrm{dd}, 6.0,3.6)$ \\
\hline $3^{\prime \prime} \alpha$ & $2.40(t, 5.9)$ & 34.94 & $3.27(\mathrm{ddd}, 13.8,8.4,3.6)$ \\
\hline $3^{\prime \prime} \beta$ & $2.40(t, 5.9)$ & & $2.65(\mathrm{dt}, 13.8,6.0)$ \\
\hline $4^{\prime \prime}$ & $4.52(t, 5.9)$ & 28.25 & $5.07(\mathrm{t}, 7.2)$ \\
\hline $5^{\prime \prime}$ & $6.98(\mathrm{~d}, 8.4)$ & 130.73 & $7.67(\mathrm{~d}, 7.8)$ \\
\hline $6^{\prime \prime}$ & $6.45(\mathrm{dd}, 8.4,2.1)$ & 104.61 & $6.85(\mathrm{dd}, 8.4,2.4)$ \\
\hline $7^{\prime \prime}-\mathrm{OH}$ & - & 156.76 & 11.35 \\
\hline $8^{\prime \prime}$ & $6.55(\mathrm{~d}, 2.1)$ & 109.82 & $7.15(\mathrm{~d}, 2.4)$ \\
\hline $9^{\prime \prime}$ & - & 156.25 & - \\
\hline $10^{\prime \prime}$ & - & 112.98 & - \\
\hline $1^{\prime \prime \prime}$ & - & 140.81 & - \\
\hline $2^{\prime \prime \prime} / 6^{\prime \prime \prime}$ & $7.35-7.42^{\mathrm{c}}$ & 126.00 & $7.24-7.42^{\mathrm{c}}$ \\
\hline $3^{\prime \prime \prime} / 5^{\prime \prime \prime}$ & $7.35-7.42^{\mathrm{c}}$ & 128.69 & $7.24-7.42^{\mathrm{c}}$ \\
\hline $4^{\prime \prime \prime}$ & $7.35-7.42^{\mathrm{c}}$ & 127.93 & $7.24-7.42^{c}$ \\
\hline
\end{tabular}

a $1 \mathrm{H}-\mathrm{NMR}(500 \mathrm{MHz})$ and ${ }^{13} \mathrm{C}-\mathrm{NMR}(125 \mathrm{MHz})$ in $\mathrm{CDCl}_{3} .{ }^{\text {b } 1} \mathrm{H}-\mathrm{NMR}(600 \mathrm{MHz})$ in Pyridine- $d_{5} .{ }^{\mathrm{c}}$ Overlapped signals.

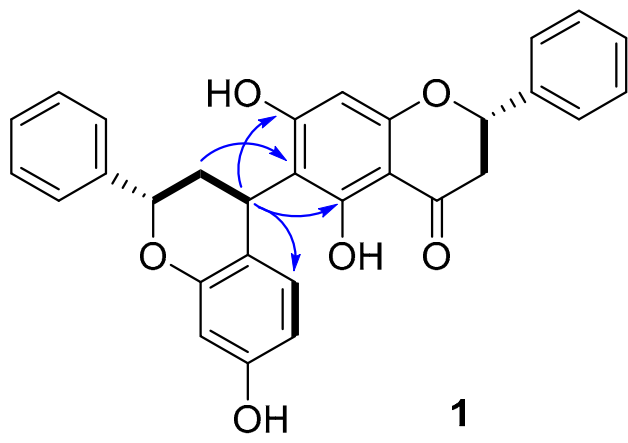

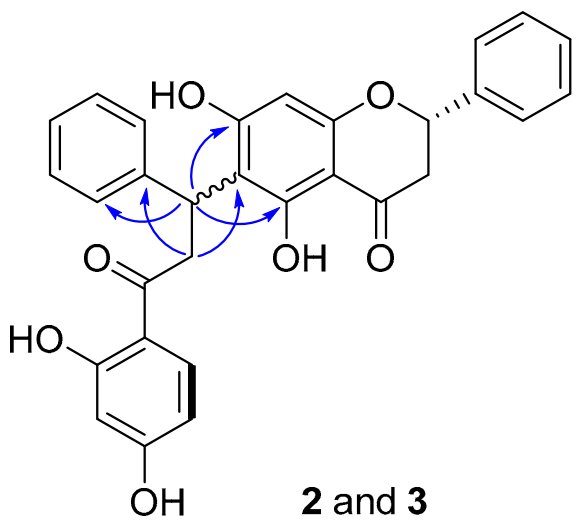

\section{${ }^{1} \mathrm{H}-{ }^{1} \mathrm{H} \operatorname{COSY}(\square) \mathrm{HMBC}(\frown)$}

Figure 2. Key ${ }^{1} \mathrm{H}-{ }^{1} \mathrm{H}$ COSY $\left({ }^{1} \mathrm{H}_{-}{ }^{1} \mathrm{H}\right.$ Correlation Spectroscopy) and HMBC correlations of compounds 1-3.

Oxytrochalcoflavanones A (2) and B (3), yellow amorphous powders with the same molecular formula of $\mathrm{C}_{30} \mathrm{H}_{24} \mathrm{O}_{7}$ based on the negative HR-ESIMS data, were also found to be biflavonoids. The UV, ECD (Electric Circular Dichroism), ${ }^{1} \mathrm{H}$ and ${ }^{13} \mathrm{C}-\mathrm{NMR}$ spectra of $\mathbf{2}$ and 3 (Table 2) were almost identical, but with the opposite optical rotations $\left([\alpha]^{20} \mathrm{D}-68.6\right.$ for $2 ;[\alpha]^{20} \mathrm{D}+51.9$ for 3$)$. The main differences 
between the ${ }^{1} \mathrm{H}$ - and ${ }^{13} \mathrm{C}-\mathrm{NMR}$ data of $\mathbf{2 , 3}$ and $\mathbf{1}$ were the presence of signals for a $2^{\prime}, 4^{\prime}$-dihydroxy dihydrochalcone moiety in 2 and 3 instead of those for the 7-hydroxy flavane moiety in 1. Identical HMBC correlations between $\mathrm{H}-\beta$ and $\mathrm{C}-5, \mathrm{C}-7$, and between $\mathrm{H}-\alpha$ and $\mathrm{C}-6$ in 2 and 3 defined the same connectivity of C- $\beta$ and C-6 in 2 and 3, which was supported by the characteristic fragment ions at $m / z 239.0350$ and 255.0667 in targeted MS/MS spectra attributed to the bond cleavage of C-6 and $C-\beta$. Thus, the same planar structures of $\mathbf{2}$ and $\mathbf{3}$ were defined as shown in Figure 1. Accordingly, the $2 S$ configurations of 2 and 3 were assigned based on the Cotton effect (Figure 3) [8]. The absolute configuration of $C-\beta$ could not be determined by comparing the experimental and calculated ECD spectra due to the close similarity in their ECD curves (Figure 3) and attempts to get single crystals of 2 and 3 also failed. Consequently, compounds 2 and 3 were characterized as the C- $\beta$ epimers, but with undefined absolute configuration of $C-\beta$.

Compounds 1-3 were obtained under the guidance of LC-QTOF/MS in negative ionization mode by extracting the corresponding deprotonated molecular ion $[\mathrm{M}-\mathrm{H}]^{-}$. Other potential biflavonoids with different skeletons and substituents were also analyzed but not detected, which might be due to the much low abundance in the herb. Biosynthetically, compounds 1-3 were proposed to be derived from compound 4 via reduction of the C-4 carbonyl group, formation of 4-2 by dehydration, and then coupled with 5 and 6 respectively (Scheme 1). This biosynthetic hypothesis is supported by the isolation of compounds 4-6 from this herb.

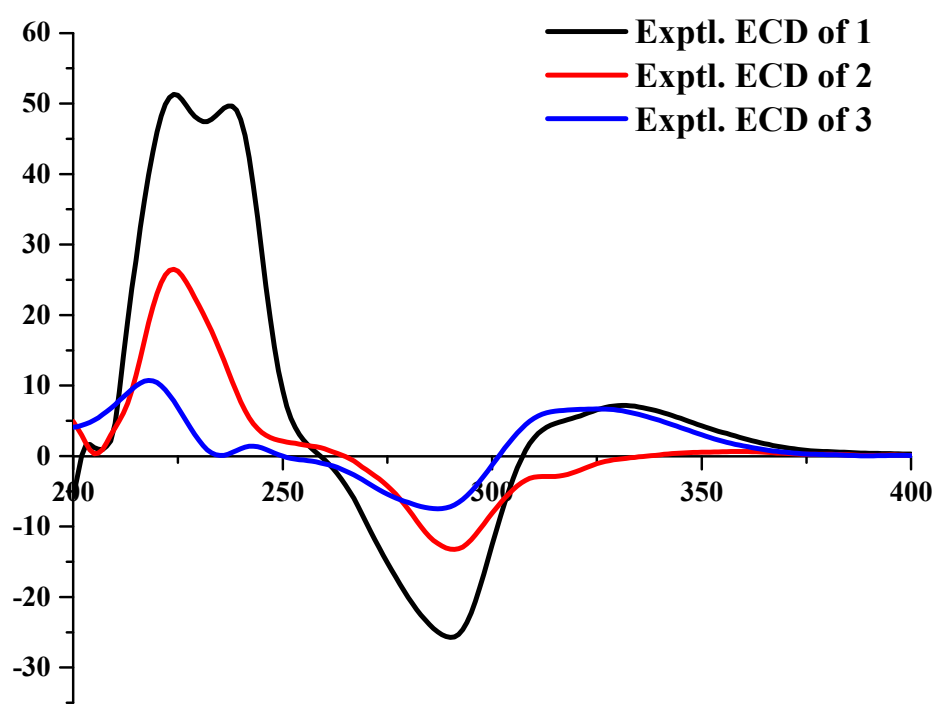

Figure 3. ECD spectra of compounds 1-3.

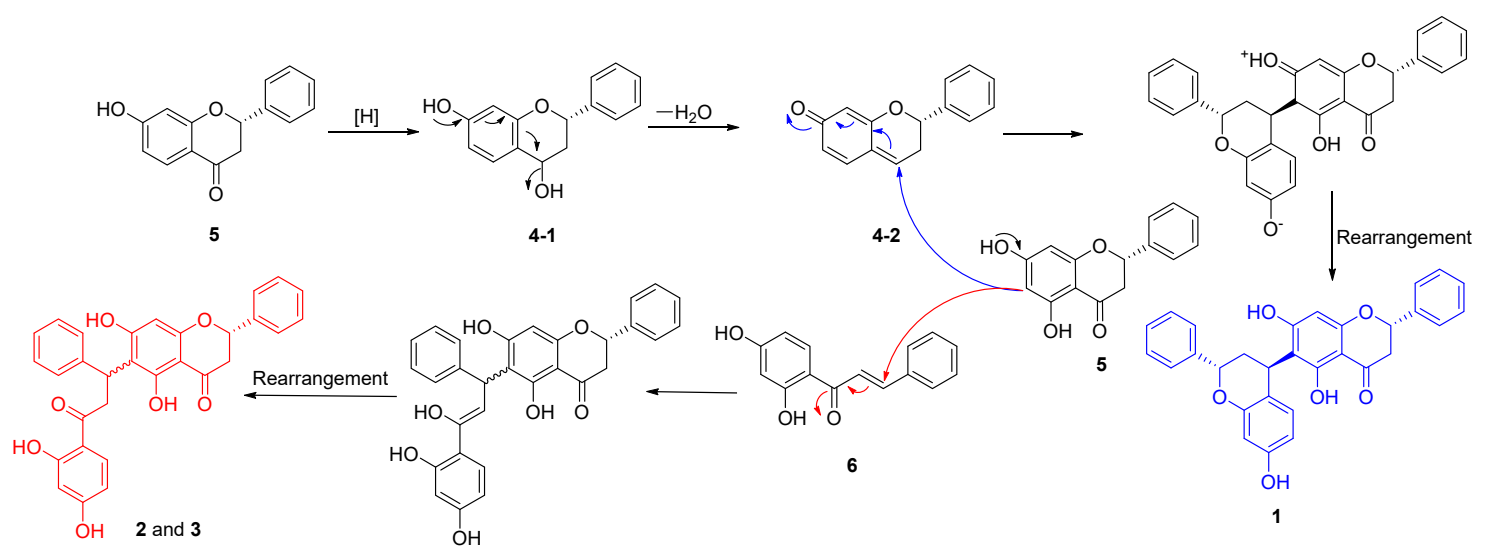

Scheme 1. Plausible biosynthetic pathway of compounds 1-3. 
Table 2. ${ }^{1} \mathrm{H}-\mathrm{NMR}(500 \mathrm{MHz})$ and ${ }^{13} \mathrm{C}-\mathrm{NMR}(125 \mathrm{MHz})$ data for oxytrochalcoflavanones A (2) and B (3) $\left(\delta\right.$ in ppm, $J$ in $\mathrm{Hz}$, in $\mathrm{CDCl}_{3}$ ).

\begin{tabular}{|c|c|c|c|c|c|}
\hline No. & ${ }^{1} \mathrm{H}-\mathrm{NMR}$ & ${ }^{13} \mathrm{C}-\mathrm{NMR}$ & No. & ${ }^{1} \mathrm{H}-\mathrm{NMR}$ & ${ }^{13} \mathrm{C}-\mathrm{NMR}$ \\
\hline 1 & - & - & $\mathrm{H}-\beta$ & $5.10(\mathrm{dd}, 9.4,4.6)$ & 34.51 \\
\hline 2 & $5.35(\mathrm{dd}, 13.2,2.8)$ & 79.22 & $H-\alpha^{a}$ & $4.25(\mathrm{dd}, 17.5,9.4)$ & 40.03 \\
\hline $3 \alpha$ & $3.09(\mathrm{dd}, 17.1,13.2)$ & 43.59 & $H-\alpha^{b}$ & $3.73(\mathrm{dd}, 17.5,4.6)$ & \\
\hline $3 \beta$ & $2.84(\mathrm{dd}, 17.1,2.8)$ & & $1^{\prime \prime}$ & - & 142.36 \\
\hline 4 & - & 196.19 & $2^{\prime \prime} / 6^{\prime \prime}$ & $7.37-7.42^{\mathrm{a}}$ & 127.86 \\
\hline 5 & - & 162.23 & $3^{\prime \prime} / 5^{\prime \prime}$ & $7.37-7.42^{\mathrm{a}}$ & 128.37 \\
\hline 6 & - & 111.05 & $4^{\prime \prime}$ & $7.37-7.42^{\mathrm{a}}$ & 126.46 \\
\hline 7 & - & 163.20 & $1^{\prime \prime \prime}$ & - & 114.07 \\
\hline 8 & $6.05(\mathrm{~s})$ & 96.89 & $2^{\prime \prime \prime}$ & - & 165.34 \\
\hline 9 & - & 161.51 & $3^{\prime \prime \prime}$ & $6.34(\mathrm{~d}, 1.0)$ & 103.68 \\
\hline 10 & - & 103.48 & $4^{\prime \prime \prime}$ & - & 163.23 \\
\hline $1^{\prime}$ & - & 138.51 & $5^{\prime \prime \prime}$ & $6.40(\mathrm{dd}, 8.9,1.0)$ & 108.21 \\
\hline $2^{\prime} / 6^{\prime}$ & $7.37-7.42^{\mathrm{a}}$ & 126.27 & $6^{\prime \prime \prime}$ & $7.83(\mathrm{~d}, 8.9)$ & 132.74 \\
\hline $3^{\prime} / 5^{\prime}$ & $7.37-7.42^{\mathrm{a}}$ & 129.01 & $5-\mathrm{OH}$ & $12.46(\mathrm{~s})$ & \\
\hline $4^{\prime}$ & $7.37-7.42^{\mathrm{a}}$ & 129.01 & $2^{\prime \prime \prime}-\mathrm{OH}$ & $12.40(\mathrm{~s})$ & \\
\hline
\end{tabular}

All the isolated compounds were evaluated for cytotoxic activities against PC-3 human prostate cancer cell line. Compounds 1 and 3 exhibited potent cytotoxicity with $\mathrm{IC}_{50}$ values of $6.64 \mu \mathrm{M}$ and $2.98 \mu \mathrm{M}$ (Figure S16, Table S1), whereas compound 2 showed moderate cytotoxicity whose $\mathrm{IC}_{50}$ value was not calculated.

\section{Experimental Section}

\subsection{General Experimental Procedures}

Optical rotations were measured on an Autopol III Rudolph Automatic polarimeter. ECD data were acquired on a Jasco 810 CD spectrophotometer. UV spectra were recorded using a Shimadzu SPD-M10A spectrophotometer. NMR spectra were recorded on Bruker Plus-400 or Advance-500 NMR spectrometer using $\mathrm{CDCl}_{3}$ as solvents. Chemical shift values were given in $\delta(\mathrm{ppm})$ using the solvent peak signals as references, and coupling constants were reported in Hz. HR-ESIMS experiments were conducted on an Agilent 6538 QTOF mass spectrometer. Column chromatography was performed on silica gel (100-200 mesh or 200-300 mesh, Qingdao Marine Chemical Co. Ltd., Qingdao, China), ODS-A

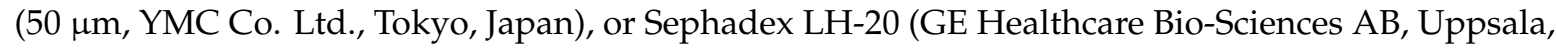
Sweden). Preparative HPLC was carried out using a GRACE Alltima RP-C18 column $(10 \times 250 \mathrm{~mm}$, $5 \mu \mathrm{m}$ ) on a JASCO PU-1580 LC instrument with a diode array detector (DAD) or a CHIRALPAK ID $(4.6 \times 250 \mathrm{~mm}, 5 \mu \mathrm{m}$, Daicel Chemical Ind., Ltd., Tokyo, Japan $)$ on a Jasco HPLC system coupled with a single wavelength detector. TLC analyses were carried out on pre-coated silica gel GF254 plates (Qingdao Marine Chemical Co. Ltd., Qingdao, China). Reagents used in HPLC and LC-MS analyses were of HPLC-grade purchased from J. T. Baker. Deionized water was purified by a Milli-Q system (Bedford, MA, USA). All other solvents used for isolation and analysis were of analytical grade purchased from Beijing Fine Chemicals (Beijing, China), and used without further purification. The $\mathrm{CDCl}_{3}$ used in the NMR studies were purchased from Cambridge Isotope Laboratories, Inc. (Andover, MA, USA).

\subsection{Plant Material}

The whole plants of O. chiliophylla were collected from Nagarzê County of Tibet Autonomous Region, People's Republic of China. The plants were immediately air-dried and stored in a warehouse at room temperature out of direct sunlight. The authenticity of the herb was confirmed by Associate Prof. Yingtao Zhang, Department of Natural Medicines, School of Pharmaceutical Sciences, Peking 
University Health Science Center, and a voucher specimen (No. 20120901) was deposited in the Herbarium of the Department of Natural Medicines, School of Pharmaceutical Sciences, Peking University Health Science Center.

\subsection{Extraction and Isolation}

The isolation of biflavonoids (1-3) was guided by LC-QTOF/MS. Each fraction was analyzed by LC-QTOF/MS through extraction of the quasi-molecular ions and then purified by repeated chromatography. The air-dried aerial parts of O. chiliophylla $(10.0 \mathrm{~kg})$ were pulverized and extracted with $95 \% \mathrm{EtOH}$ and $50 \% \mathrm{EtOH}$ successively to afford two crude extracts. After concentration in vacuum, the $95 \% \mathrm{EtOH}$ and $50 \% \mathrm{EtOH}$ extracts were separately suspended in water and partitioned sequentially with petroleum ether $(40 \mathrm{~L} \times 3)$, EtOAc $(50 \mathrm{~L} \times 3)$, and $\mathrm{n}-\mathrm{BuOH}(60 \mathrm{~L} \times 3)$. The EtOAc fractions were combined $(900 \mathrm{~g})$ and subjected to silica gel column chromatography eluted with a gradient system of petroleum ether/EtOAc (from 10:1 to 1:5, v/v) to afford fractions A-H. Fraction C $(15.0 \mathrm{~g})$ was purified by Sephadex LH-20 column chromatography eluted with an isocratic elution of petroleum ether $/ \mathrm{CH}_{2} \mathrm{Cl}_{2} / \mathrm{MeOH}$ (5:5:1, v/v/v) to yield subfractions Ca-Cf. Purification of subfractions $\mathrm{Ce}-\mathrm{Cf}$ by semi-preparative HPLC eluting with a $\mathrm{MeOH} / \mathrm{H}_{2} \mathrm{O}$ system yielded compound $\mathbf{1}(1.2 \mathrm{mg})$ and the mixture of compounds 2 and $\mathbf{3}$. Failed in the separation of 2 and 3 by a conventional RP-C18 column, compounds $2(0.8 \mathrm{mg})$ and $3(0.4 \mathrm{mg})$ were resolved by chiral-phase HPLC using a CHIRALPAK ID column $(4.6 \times 250 \mathrm{~mm})$. Fraction G $(5.0 \mathrm{~g})$ was subjected to repeated Sephadex LH-20 column chromatography eluted with an isocratic elution of petroleum ether $/ \mathrm{CH}_{2} \mathrm{Cl}_{2} / \mathrm{MeOH}(5: 5: 1, v / v / v)$ to give compounds 4 (100.3 mg), 5 (302.5 mg), and 6 (200.1 mg).

Oxytrodiflavanone A (1): yellow amorphous powders; $[\alpha]^{20}{ }_{\mathrm{D}}+70.0$ (c $\left.0.1, \mathrm{MeOH}\right) ; \mathrm{UV}(\mathrm{MeOH})$ 235, $283 \mathrm{~nm}$; (-)-HR-ESIMS m/z 479.1499 [M - H] ${ }^{-}$(calcd for $\mathrm{C}_{30} \mathrm{H}_{23} \mathrm{O}_{6}, 479.1500$ ); ${ }^{1} \mathrm{H}$ - and ${ }^{13} \mathrm{C}-\mathrm{NMR}$ data see Table 1.

Oxytrochalcoflavanone A (2): yellow, amorphous powders; $[\alpha]^{20}{ }_{\mathrm{D}}-68.6$ (c 0.1, MeOH); UV (MeOH) 235, $283 \mathrm{~nm}$; (-)-HR-ESIMS m/z 495.1453 [M - H] $]^{-}$(calcd for $\mathrm{C}_{30} \mathrm{H}_{23} \mathrm{O}_{7}, 495.1449$ ); ${ }^{1} \mathrm{H}$ - and ${ }^{13}$ C-NMR data see Table 2.

Oxytrochalcoflavanone B (3): yellow amorphous powders; $[\alpha]^{20}{ }_{\mathrm{D}}+51.9$ (c $\left.0.1, \mathrm{MeOH}\right)$; UV (MeOH) 235, $283 \mathrm{~nm}$; (-)-HR-ESIMS m/z 495.1453 [M - H] $]^{-}$(calcd for $\mathrm{C}_{30} \mathrm{H}_{23} \mathrm{O}_{7}, 495.1449$ ); ${ }^{1} \mathrm{H}$ - and ${ }^{13}$ C-NMR data see Table 2.

\subsection{Cytotoxicity Assays against PC-3 Human Prostate Cancer Cells}

Human prostate cancer cell line PC-3 was obtained from the American Type Culture Collection (Manassas, VA, USA) and grown according to the recommended guidelines. Cells were cultured in RPMI 1640 medium (HyClone, Cramlington, UK) supplemented with 10\% (v/v) foetal bovine serum (Biological Industries, Kibbutz Beit-Haemek, Israel), $10 \mu \mathrm{g} / \mathrm{mL}$ streptomycin and $100 \mathrm{U} / \mathrm{mL}$ penicillin at $37^{\circ} \mathrm{C}$ in a humidified atmosphere containing $5 \% \mathrm{CO}_{2}$. Cell viability was determined using MTT assay [14]. Briefly, following treatment of PC3 cells with various concentrations of the tested drugs for $48 \mathrm{~h}$ in 96 well plates, MTT was added to each well at a final concentration of $0.5 \mathrm{mg} / \mathrm{mL}$. After incubated for $4 \mathrm{~h}$ at $37^{\circ} \mathrm{C}$, the culture medium was removed, and the purple formazan crystals were dissolved in $150 \mu \mathrm{L}$ of DMSO. The absorbance of the resulting solution was measured at $490 \mathrm{~nm}$ by a microplate reader (iMark, Bio-Rad, Hercules, CA, USA). Cell viability (\%) and cell growth inhibition (\%) were calculated using the following formulas:

Cell viability $(\%)=100 \times$ (absorbance of a given sample - absorbance of blank well)/(absorbance of control well - absorbance of blank well), Cell growth inhibition ( $\%)=100 \%$ - Cell viability (\%), where the blank well contained medium but no cells and the control well-contained cells but no drug. The $\mathrm{IC}_{50}$ values were calculated by fitting the data points to a logistic curve using GraphPad Prism 5 software (GraphPad Software, San Diego, CA, USA). ZSTK474, an antitumor agent in clinical trials, was used as the positive control. 


\section{Conclusions}

Three previously undescribed biflavonoids, oxytrodiflavanone A (1), and oxytrochalcoflavanones $\mathrm{A}, \mathrm{B}(\mathbf{2}, 3)$, along with their putative biosynthetic monomers (4-6), were isolated from the aerial parts of O. chiliophylla guided by LC-QTOF/MS. Compounds $\mathbf{1}$ and $\mathbf{3}$ exhibited potent cytotoxicity against PC-3 human prostate cancer cell line with $\mathrm{IC}_{50}$ values of $6.64 \mu \mathrm{M}$ and $2.98 \mu \mathrm{M}$.

Supplementary Materials: 1D- and 2D-NMR spectra, targeted MS/MS spectra, and the raw data about cell growth inhibitory activities are available online.

Author Contributions: Conceptualization, Y.L. Y.Z., H.L., P.T., D.K. and Q.Z.; Funding Acquisition, P.T., D.K., and Q.Y.; Investigation, Y.L., N.K., J.L.; Project Administration, D.K. and Q.Z.; Writing-Original Draft, Y.L.

Funding: This work was financially supported by National Natural Sciences Foundation of China (No. 21372015, 81373441 and 81872978) and National Key Technology R \& D Program “New Drug Innovation" of China (No. 2017ZX 09101003-008-003).

Acknowledgments: We sincerely thank G. Tu at Beijing Institute of Microchemistry for measuring the NMR data.

Conflicts of Interest: The authors declare no conflict of interest.

\section{References}

1. Committee of Chinese Pharmacopoeia. Chinese Pharmacopoeia; Chinese Medical Science and Technology Press: Beijing, China, 2015.

2. Dimaer, D.Z.P.C. Jingzhu Materia Medica; Shanghai Science and Technology Press: Shanghai, China, 1986.

3. The Chinese Academy of Sciences. Flora of China; Science Press: Beijing, China, 2005.

4. Yao, S.; Ma, Y.; Tang, Y.; Chen, J.; Zhang, X. Chemical constituents of Oxytropis chiliophylla. Chin. J. Chin. Mater. Med. 2007, 32, 1660-1662.

5. Kelsang, N.; Que, S.; Kelsang, P.; Zhang, X.; Samnor; Liang, H.; Zhang, Q. High-performance liquid chromatographic fingerprint analysis of Oxytropis falcata Bunge and Oxytropis chiliophylla Royle. J. Chin. Pharm. Sci. 2014, 23, 783-789.

6. Wang, J.; Liu, Y.; Kelsang, N.; Zeng, K.; Liang, H.; Zhang, Q.; Tu, P. Rhamnocitrin glycosides from Oxytropis chiliophylla. Phytochem. Lett. 2017, 19, 50-54. [CrossRef]

7. Liu, Y.; Zhang, X.; Kelsang, N.; Tu, G.; Kong, D.; Lu, J.; Zhang, Y.; Liang, H.; Tu, P.; Zhang, Q. Structurally diverse cytotoxic dimeric chalcones from Oxytropis chiliophylla. J. Nat. Prod. 2018, 81, 307-315. [CrossRef] [PubMed]

8. Seo, E.; Silva, G.; Chai, H.; Chagwedera, T.; Farnsworth, N.; Cordell, G.; Pezzuto, J.; Kinghorn, A. Cytotoxic prenylated flavanones from Monotes engler. Phytochemistry 1997, 45, 509-515. [CrossRef]

9. Meesakul, P.; Pudhom, K.; Pyne, S.; Laphookhieo, S. Hybrid flavan-flavanones from Friesodielsia desmoids and their inhibitory activities against nitric oxide production. RSC Adv. 2017, 7, 17545-17550. [CrossRef]

10. Bajgai, S.; Prachyawarakorn, V.; Mahidol, C.; Ruchirawat, S.; Kittakoop, P. Hybrid flavan-chalcones, aromatase and lipoxygenase inhibitors, from Desmos cochinchinensis. Phytochemistry 2011, 72, 2062-2067. [CrossRef] [PubMed]

11. Ding, Y.; Li, X.; Ferreira, D. 4-Arylflavan-3-ols as proanthocyanidin models: Absolute configuration via density functional calculation of electronic circular dichroism. J. Nat. Prod. 2010, 73, 435-440. [CrossRef] [PubMed]

12. Pesca, M.S.; Piaz, F.D.; Sanogo, R.; Vassallo, A.; De Abreu, M.B.; Rapisarda, A.; Germanó, M.P.; Certo, G.; Falco, S.D.; De Tommasi, N.; et al. Bioassay-guided isolation of proanthocyanidins with antiangiogenic activies. J. Nat. Prod. 2013, 76, 29-35. [CrossRef] [PubMed]

13. Coetzee, J.; Steynberg, J.P.; Steynberg, P.J.; Brandt, E.V.; Ferreira, D. Oligomeric flavonoids. Part 18. Dimeric prorobinetinidins from Robinia pseudacacia. Tetrahedron 1995, 51, 2339-2352. [CrossRef]

14. Liu, Y.; Nair, M.G. An efficient and economical MTT assay for determining the antioxidant activity of plant natural product extracts and pure compounds. J. Nat. Prod. 2010, 73, 1193-1195. [CrossRef] [PubMed]

Sample Availability: Samples of the compounds are available from the authors. 